\title{
Upper airway size and collapsibility in snorers: evaluation with digital fluoroscopy
}

\author{
Y. Tsushima*, J. Antila**, E. Svedström*, A. Vetriö*, E. Laurikainen**, \\ O. Polo+, M. Kormano*
}

Upper airway size and collapsibility in snorers: evaluation with digital fluoroscopy. $Y$. Tsushima, J. Antila, E. Svedström, A. Vetriö, E. Laurikainen, O. Polo, M. Kormano. ABSTRACT: This study addressed the question of whether there are any differences in the size and collapsibility of the upper airway measured by digital fluoroscopy, between snorers and controls whilst they were awake and breathing normally; and whether there are any correlations between these measurements and other clinical data.

The dynamic changes of the upper airway size were evaluated using digital fluoroscopy in 33 patients and $\mathbf{1 6}$ normal controls. The measurements were compared with findings in an overnight sleep study, including a static-charge-sensitive bed (SCSB) and oximeter recordings.

The minimum anteroposterior dimension at the velopharyngeal level was smaller in patients with partial upper airway obstruction than in controls $(\mathrm{p}<0.005)$; patients with complete obstruction did not differ from the controls. The velopharyngeal airways were also more collapsible in patients with severe partial obstruction $(\mathbf{p}<0.01)$ than in controls. At the oropharyngeal and hypopharyngeal levels, the dimensions and the collapsibilities were similar in patients and controls. The velopharyngeal collapsibility correlated with body mass index $(p<0.001)$, whereas the airway size did not. The velopharyngeal collapsibility was more pronounced in patients with frequent episodes of arterial oxyhaemoglobin desaturation during sleep.

Velopharyngeal collapsibility associated with high body mass index was the important determinant of nocturnal breathing disturbances. Digital fluoroscopy displays the dynamic changes of the upper airways throughout the respiratory cycle.

Eur Respir J., 1996, 9, 1611-1618.
Depts of *Diagnostic Radiology, **Otorhinolaryngology and +Respiratory Diseases, Turku University Hospital, Turku, Finland.

Correspondence: Y. Tsushima

Dept of Radiology

National Defense Medical College

3-2 Namiki

Tokorozawa

Saitama 359

Japan

Keywords: Airway-collapsibility digital fluoroscopy

sleep apnoea

snoring

static-charge-sensitive bed

Received: July 211995

Accepted after revision May 21996
Snoring is defined as sounds made by vibrations in the soft palate and posterior faucial pillars during sleep. Heavy snoring is a result of sleep-related upper airway narrowing, which leads to respiratory flow limitation and increased respiratory effort. Strong inspiratory suction may, secondarily, cause a total upper airway collapse, causing an episode of obstructive sleep apnoea (OSA). If untreated, heavy snoring may be complicated by excessive daytime sleepiness or increased blood pressure.

Obesity is a considerable risk factor for snoring with and without OSA. Both functional and anatomical factors are involved in the pathophysiology of upper airway obstruction $[1,2]$. Various techniques which range from direct visual inspection to sophisticated imaging, have been used to evaluate the structural and functional properties of the upper airway [2]. Cephalometric roentgenograms demonstrate the skeletal and soft tissue structures of the upper airway. Using this technique, mandibular deficiency, elongation of the soft palate (and uvula), narrowed posterior airway space and an inferiorly positioned hyoid bone have been shown to be frequent in patients with OSA [3-8]. Snorers with and without OSA may have a narrower pharynx during sleep as well as during wakefulness, although the results of previous studies of upper airway size are conflicting [9-18].
Snorers with and without OSA have a more collapsible pharyngeal airway than nonsnorers. Although the reason for this increased collapsibility is unclear, it has been suggested that the increase of upper airway collapsibility plays a key role in the aggravation of snoring and OSA $[1,19,20]$. In prior studies into upper airway collapsibility, negative or positive pressures were applied to the upper airway which would upset normal physiological conditions [19, 21-28]. Dynamic upper airway imaging using ultrafast computed tomography (CT) has demonstrated that the upper airways of snorers with and without OSA are more collapsible than the upper airways of nonsnorers, even during awake respiration [9, 10]. However, this sophisticated imaging modality is not yet widely available. The cost is high, and only transverse images can be obtained.

We developed the digital fluoroscopy technique during awake respiration in order to measure the size and collapsibility of the pharyngeal airway. The goal of our study is to give a clue to elucidating the pathogenesis of snoring and OSA, in particular to answering the question why obesity is the major risk factor of snoring and OSA. The digital fluoroscopy results in the patients and controls were compared with the overnight sleep study and body mass index (BMI). 


\section{Materials and methods}

\section{Subjects}

Thirty males and 3 females were included in the study (average age 48 yrs, range 29-63 yrs). Subjectively, all patients suffered from excessive sleepiness. They had all undergone sleep study and had been referred for otorhinolaryngological evaluation and possible operative treatment. An otorhinolaryngological examination was made by the same consultant specialist (JA), and it was ensured that no patient had an obstruction in nasal cavity on inspection. Their nocturnal motor activity, heart beat and breathing patterns were monitored with a staticcharge-sensitive bed (SCSB, Biomat ${ }^{\circledR}$; Biorec, Turku, Finland) together with an ear oximeter (Biox II; the BOC Group Inc., Louisville, CO, USA). During the daytime, when the patients were awake, the upper airways were examined using digital fluoroscopy (Advantx DX, GE).

The controls, including 12 males and 4 females (average age 38 yrs, range $28-74$ yrs), who had never snored or had symptoms or signs compatible with heavy snoring or OSA, were also examined using digital fluoroscopy. They were all married, and their sleeping partners could give assurance that the controls were nonsnorers.

All subjects gave their informed consent to the study protocol, which had been approved by the Ethics Committee of Turku University Hospital.

\section{SCSB recordings}

The static-charge-sensitive bed (SCSB) is a noninvasive method for cardiorespiratory monitoring [29-34]. Body movement, respiratory movement and the heart beat (ballistocardiogram; BCG) can be obtained from the original signal. Not only episodes of apnoea or hypopnoea but also increased upper airway resistance (partial airway obstruction) without apnoea can be detected indirectly by the SCSB [34]. The validity of the SCSB signal as a marker of snoring-related dynamic changes has been tested and reported in previous articles [29-34].

The SCSB recordings were visually analysed by one of the authors (OP), who was not aware of the digital fluoroscopy findings, according to previously described criteria [31-34]. The $3 \mathrm{~min}$ episodes of various periodic breathing patterns (P-1, OP-1, OP-2, and OP-3) or the continuously increased respiratory resistance (IRR) pattern were distinguished and quantified as percentage of time in bed. A 3 minute with symmetrically waxing and waning periodic breathing was scored P-1 (Periodic Breathing type-1), if the hyperpnoeic phase was not associated with significantly increased respiratory variation of the BCG (spiky BCG). If the BCG spikes were present, the epoch was scored OP-1 (Obstructive Periodic Breathing type-1). OP-2 (Obstructive Periodic Breathing type-2) was scored if a body movement occurred immediately after the resumption of the breathing efforts, and OP-3 (Obstructive Periodic Breathing type-3), if the movement arousal occurred only after a period of increasing breathing efforts with associated spiky BCG. The IRR pattern was defined as increasing amplitude of respiratory movement associated with increasing respiratory variation of the $\mathrm{BCG}$, lasting for at least $1 \mathrm{~min}$. The $\mathrm{P}-1$ and OP-1 imply two different types of periodic hypopnoeas, whereas OP-2 and OP-3 patterns essentially correspond to periodically occurring episodes of obstructive sleep apnoea. The IRR pattern implies breathing with increased effort as a response to partially narrowed upper airways.

For the purpose of the study, the P-1, OP-1 and IRR patterns were combined and defined as episodes of partial upper airway obstruction (PO), whereas the OP-2 and OP-3 patterns combined were considered to indicate complete upper airway obstruction (CO) [31]. The subjects were divided into the following groups on the basis of the presence of snore and the findings in the SCSB recording: 1) controls, with no history of snoring or sleep disorder; 2) patients with minor partial obstruction (the frequency of PO less than $30 \%$ and CO less than $10 \%$ of time in bed); 3) patients with major partial obstruction (the frequency of PO equal to or more than $30 \%$ and $\mathrm{CO}$ less than $10 \%$ of time in bed); and 4) patients with complete obstruction (the frequency of $\mathrm{CO}$ equal to or more than $10 \%$ of time in bed).

\section{Arterial oxyhaemoglobin saturation}

Arterial oxyhaemoglobin saturation was monitored continuously during the night. Respiratory events with desaturation of $4 \%$ or more were considered, and the oxyhaemoglobin desaturation index (ODI4) was defined as the average number of such desaturations per recording hour. The fluoroscopic findings were also compared between two groups of patients using the ODI $4=10$ as cut-off point.

\section{Digital fluoroscopy}

Digital fluoroscopy was performed while the subject was awake, lying in supine position (figs. 1 and 2). The neck was placed in a neutral position, without a pillow. The subject was instructed to gently place the tip of his or her tongue behind the front teeth, whilst breathing normally through the nose without swallowing. The lateral fluoroscopic view was monitored over the course of two or three respiratory cycles, with 6,3 images $\cdot \mathrm{s}^{-1}$. The field ranged from the inferior border of the orbit to the vocal cords. A radio-opaque scale was placed just below the patient's jaw at the midline.

Analysis of the digital fluoroscopies was carefully performed by one of the authors (YT), who was not aware of the SCSB recording findings, on a monitor display with pre-existing software for distance measurement.

The two images that showed the minimum and maximum anteroposterior airway dimensions (ADmin and $\mathrm{ADmax}$, respectively) were visually selected, and $\mathrm{ADmin}$ $(\mathrm{mm})$ and ADmax $(\mathrm{mm})$ were determined at three levels: 1) the narrowest part of the velopharynx (this part was always just above the lower tip of the uvula); 2) the narrowest part of the oropharynx between the lower tip of the uvula and the upper tip of the epiglottis; and 3) the narrowest part of the hypopharynx (this part was always just below the upper tip of the epiglottis).

Because the upper airways moved synchronously at all levels, ADmin and ADmax at each anatomical level 
a)

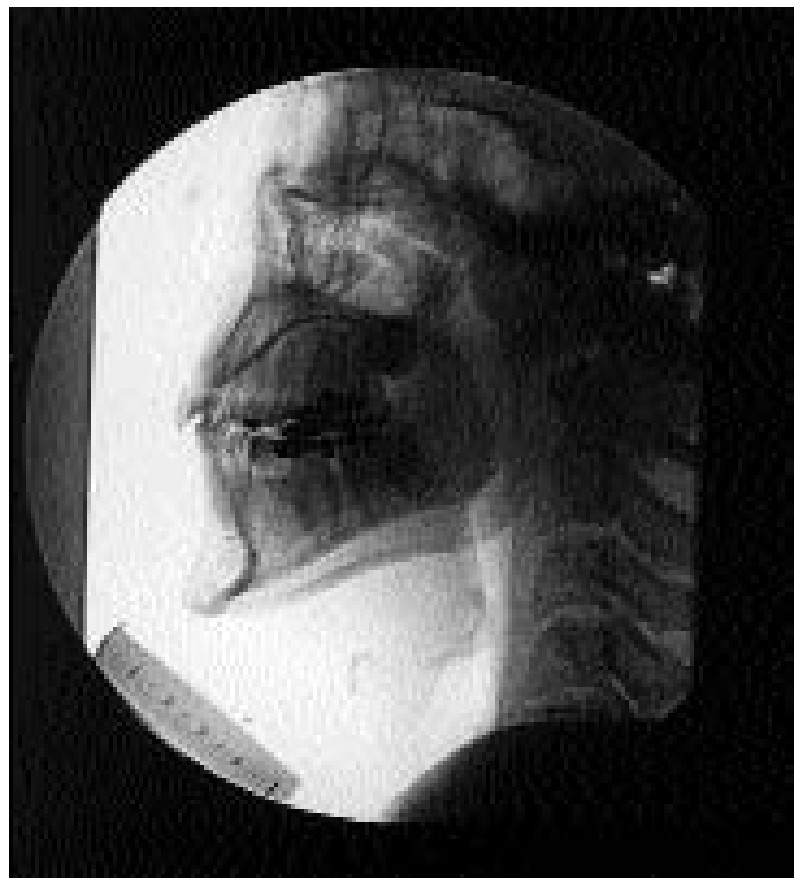

b)

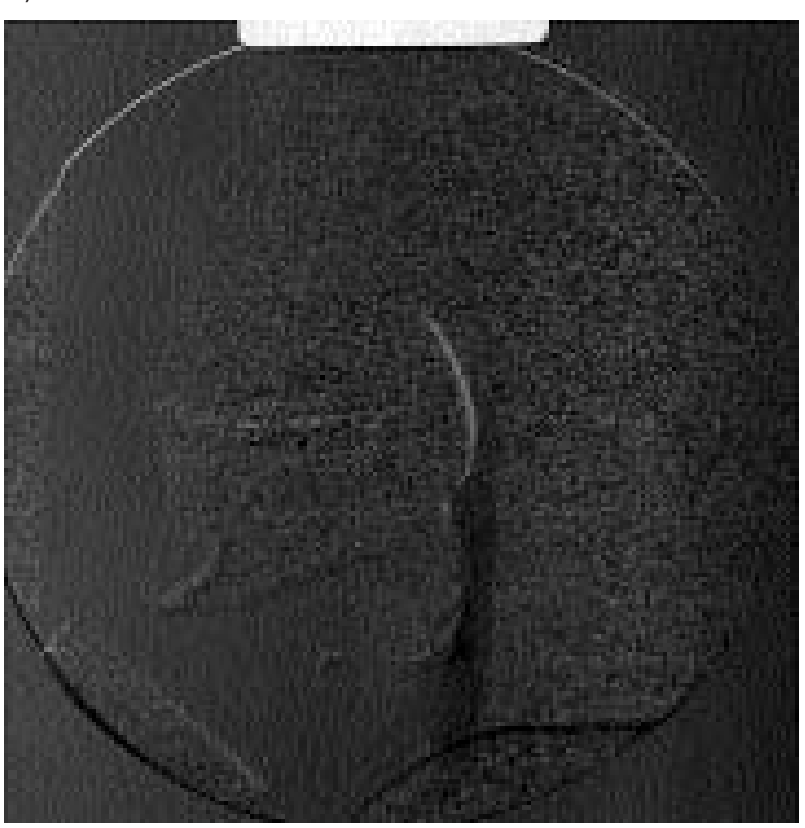

Fig. 1. - Digital fluoroscopy of the upper airway of a snorer; a) minimum image; b) subtraction image (maximum image - minimum image). This patient has a relatively large collapsibility at the velopharyngeal level (arrow). ADmin and ADmax were measured on the minimum and maximum images, respectively, although a subtraction image may be useful for selecting the minimum and maximum images from a series of fluoroscopic images. ADmin: minimum airway diameter; ADmax: maximum airway diameter.

were measured from the same minimum and maximum images. The digital subtraction technique was used to determine the images with ADmin and ADmax (figs 1 and 2 ), and to ensure that there was no head movement during examination. Collapsibility was defined as dynamic change of the airway dimension over the breathing cycle and calculated as $((\mathrm{AD} \max -\mathrm{ADmin}) / \mathrm{ADmax}) \times 100(\%)$. a)

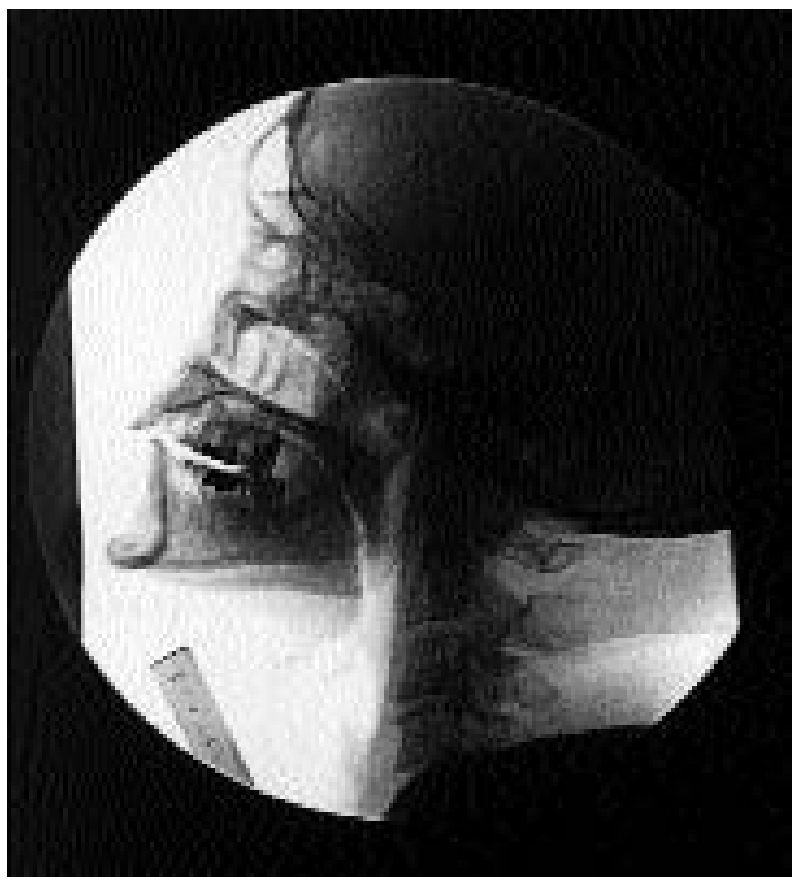

b)

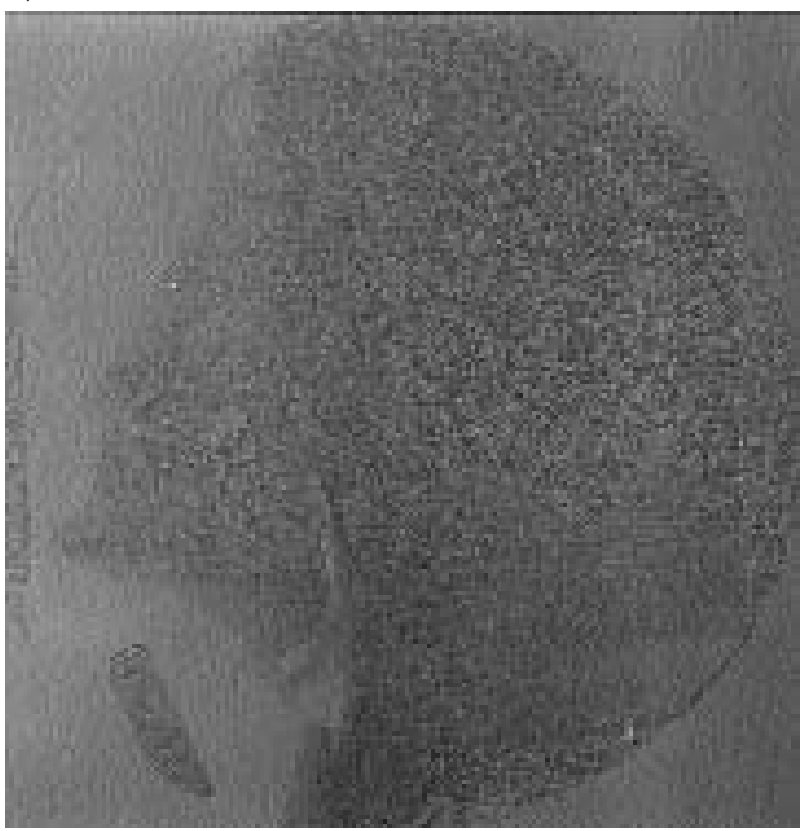

Fig. 2. - Digital fluoroscopy of the upper airway of a nonsnorer; a) minimum image; b) subtraction image (maximum image - minimum image). The upper airway of this subject moves little.

When ADmax was zero, collapsibility was defined as $0 \%$. To match for body size, the anteroposterior dimension of the second cervical vertebral body was measured at its caudal border, and the relative $\mathrm{ADmin}$ and $\mathrm{ADmax}$ were calculated.

\section{Statistical analysis}

Analysis of variance (ANOVA) followed by Bonferroni t-test was used to study the differences between the four 
Table 1. - Subject characteristics

\begin{tabular}{lcc}
\hline Variable & $\begin{array}{c}\text { Snoring subjects } \\
(\mathrm{n}=33)\end{array}$ & $\begin{array}{c}\text { Nonsnoring subjects } \\
(\mathrm{n}=16)\end{array}$ \\
\hline Age yrs & $48 \pm 9$ & $38 \pm 11 * *$ \\
Height $\mathrm{cm}$ & $178 \pm 7$ & $177 \pm 9$ \\
Weight $\mathrm{kg}$ & $90 \pm 13$ & $74 \pm 9 * *$ \\
BMI $\mathrm{kg} \cdot \mathrm{m}^{-1}$ & $28.5 \pm 3.4$ & $23.5 \pm 2.6^{* *}$ \\
\hline
\end{tabular}

Values are expressed as mean \pm SD. BMI: body mass index. **: $\mathrm{p}<0.001$.

groups divided by the findings in the SCSB recording. The results of ODI4 were analyzed by ANOVA between controls and patients with ODI $4<10$ and ODI $4 \geq 10$. Linear regression analysis was also performed. A p-value less than 0.05 was considered significant.

\section{Results}

The demographic data of the subjects are summarized in table 1 . The patients were more obese and older than the controls. According to SCSB recordings, 20 patients had minor partial obstruction (minor PO), seven presented with major partial obstruction (major PO), and in six patients the predominant breathing abnormality was complete upper airway obstruction (CO).

The ODI 4 was $<10$ in 23 patients and $\geq 10$ in the remaining 10. ODI4 correlated with BMI $(r=0.47 ; \mathrm{p}<0.01)$ and with the frequency of $\mathrm{CO}$ episodes $(\mathrm{r}=0.83 ; \mathrm{p}<0.001)$, but not with the episodes of PO. The ODI4 was larger in patients with $\mathrm{CO}(26.6 \pm 19.0)$ compared with the minor PO $(4.2 \pm 3.4)(\mathrm{p}<0.05)$ or major PO $(6.9 \pm 7.4)(\mathrm{p}<0.03)$, but no difference was observed between the minor and major PO.

In one patient, the hypopharyngeal measurements were excluded because of poor image quality.

a)

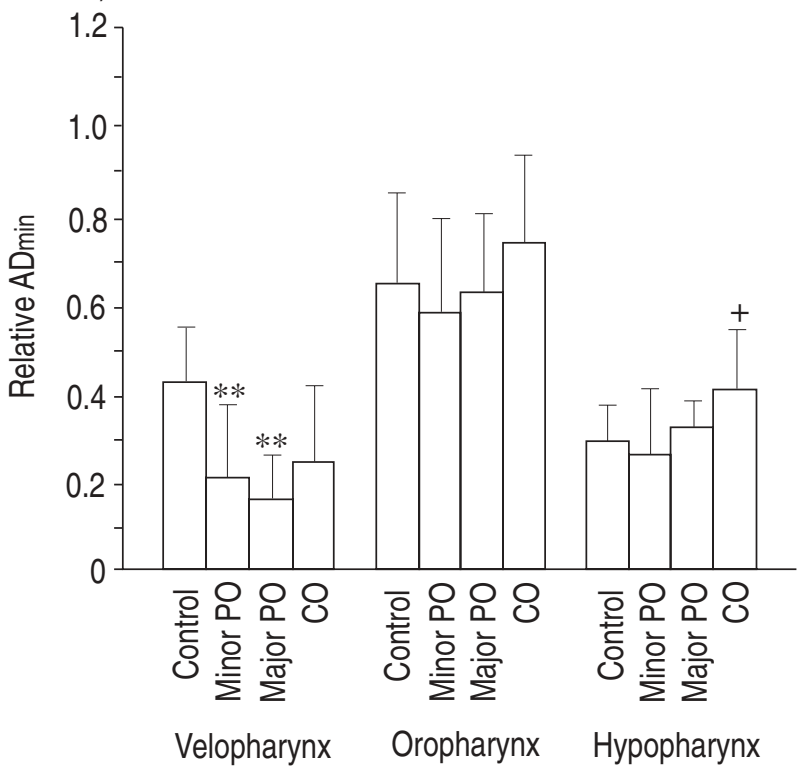

\section{Upper airway size}

The anterior walls of the pharynx (the posterior wall of the soft palate, tongue base and the posterior wall of the epiglottis) were usually moving during breathing; whereas, the posterior pharyngeal wall remained stable. ADmin occurred during inspiration and ADmax occurred during expiration. At the velopharyngeal level, the relative ADmin was smaller in patients with minor or major PO compared with controls $(\mathrm{p}<0.005)$ (fig. 3a). The relative ADmax was smaller in patients with major PO than controls $(\mathrm{p}<0.01)$ (fig. $3 b)$.

The relative ADmin at the velopharyngeal level was similar in patients with ODI $4<10$ and ODI4 $\geq 10$ but smaller than controls $(\mathrm{p}<0.003)$ (fig. 4).

At the oropharyngeal and hypopharyngeal levels, the relative $\mathrm{ADmin}$ and $\mathrm{ADmax}$ were similar in controls and patients, although the hypopharyngeal ADmin was larger in patients with $\mathrm{CO}$ than patients with minor and major PO combined $(\mathrm{p}<0.03)$ (fig. 3a).

$\mathrm{BMI}$ had no correlation to either $\mathrm{ADmin}$ or $\mathrm{ADmax}$ at any level.

\section{Collapsibility}

At the velopharyngeal level, the airway was more collapsible in patients with major PO than controls $(\mathrm{p}<0.01)$ (fig. 5). The collapsibility was increased in the patients with ODI $4 \geq 10$ compared with those with ODI4 $<10$ $(\mathrm{p}<0.03)$ and with controls $(\mathrm{p}<0.003)$ (fig. 5). Although nine patients with minor PO revealed a collapsibility = $0 \%$ at the velopharyngeal level, all patients with major PO or CO revealed a collapsibility larger than $10 \%$.

At the oropharyngeal and hypopharyngeal levels, similar trends were observed but there were no statistical differences.

The collapsibility at the velopharyngeal level correlated with BMI ( $\mathrm{r}=0.47$; $\mathrm{p}<0.001$ ) (fig. 6).

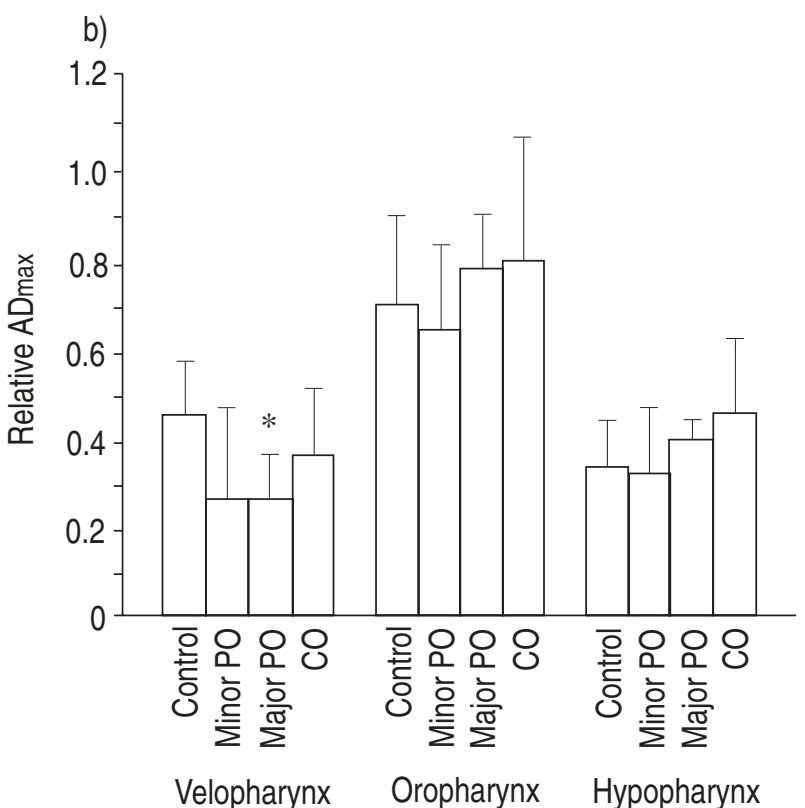

Fig. 3. - a) Comparison of the relative minimum airway dimension (ADmin) in the four groups. Minor PO: patients with minor partial obstruction; Major PO: patients with major partial obstruction; CO: patients with complete obstruction. **: different from controls, $\mathrm{p}<0.005$; +: different from patients with minor and major PO combined, $\mathrm{p}<0.03$. b) Comparison of the relative maximum airway dimension (ADmax) in the four groups. Bars indicate $\mathrm{SD}$. *: different from controls, $\mathrm{p}<0.01$. 

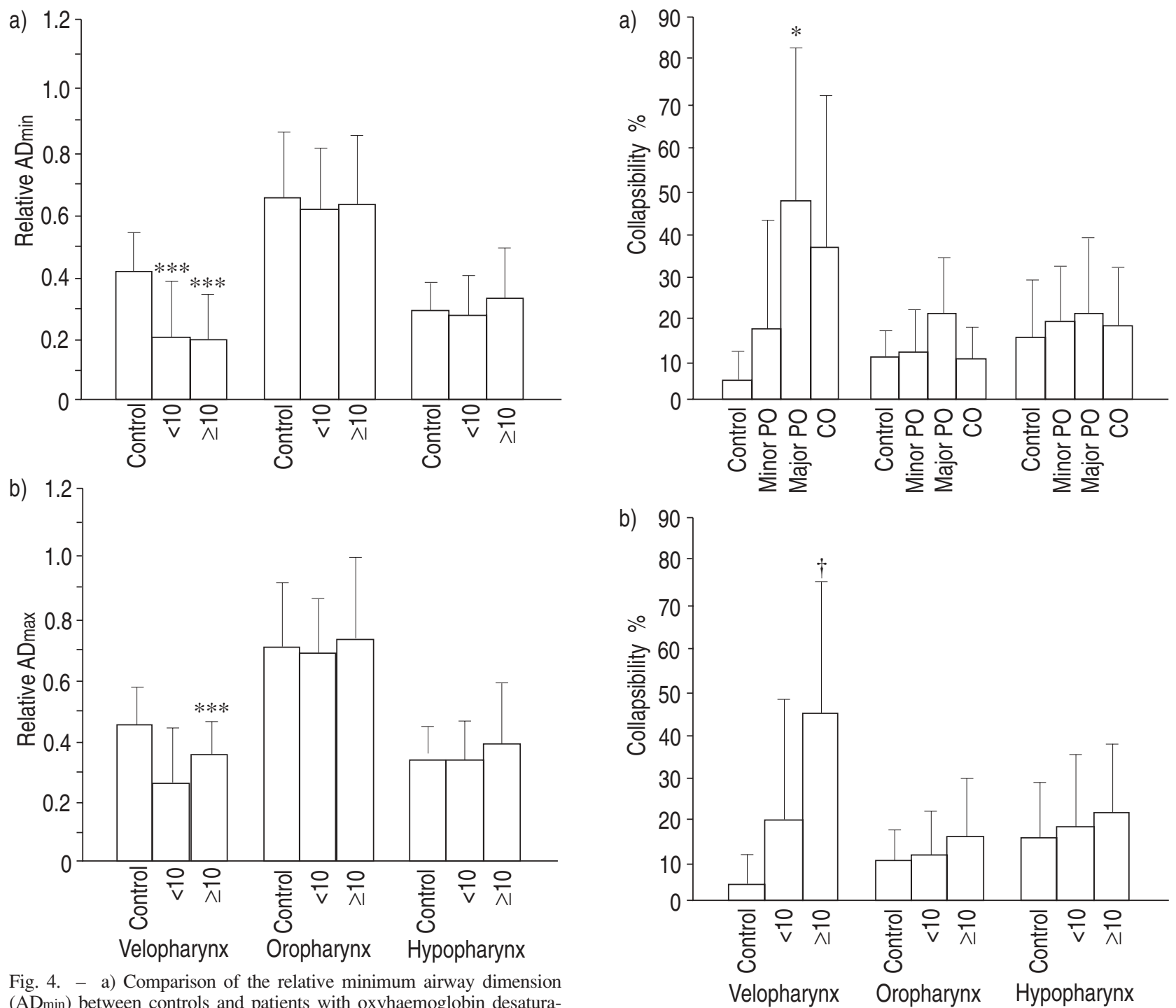

(ADmin) between controls and patients with oxyhaemoglobin desaturation index $(\mathrm{ODI} 4)<10$ and $\mathrm{ODI} 4 \geq 10 .<10$ : patients with $\mathrm{ODI} 4<10 ; \geq 10$ : patients with $\mathrm{ODI} 4 \geq 10$. b) Comparison of the relative maximum airway dimension (ADmax) between controls and patients with ODI $4<10$ and $\mathrm{ODI} 4 \geq 10$. Bars indicate SD. $* * *$ : different from controls, $\mathrm{p}<0.003$.

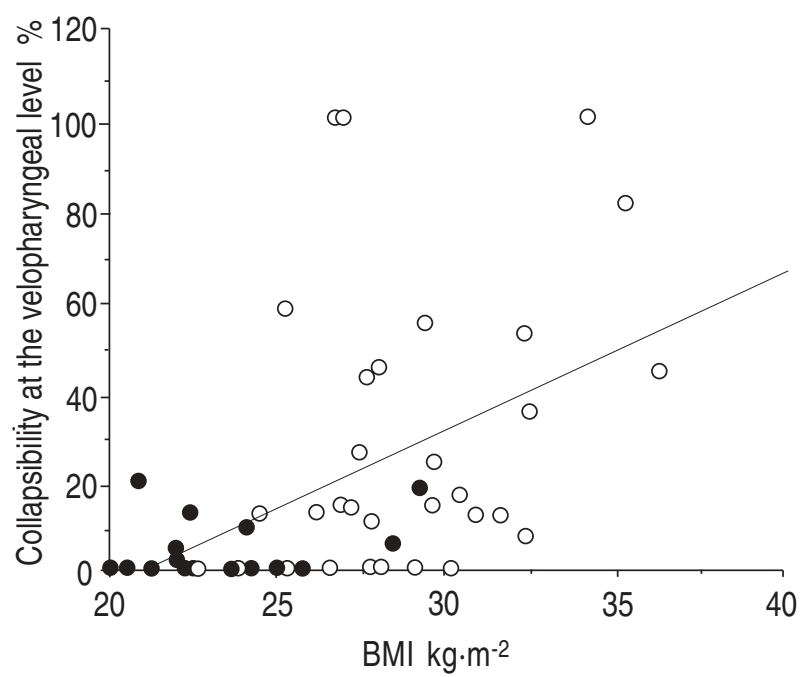

Fig. 6. - Relationship between body mass index (BMI) and the collapsibility at the velopharyngeal level (snorers and controls combined: $\mathrm{r}=0.47 ; \mathrm{p}<0.001 ; \mathrm{n}=49$ ). $\bigcirc$ : snorers; $\bullet$ : controls.

Fig. 5. - a) Comparison of upper airway collapsibility in the four groups. *: different from controls, $\mathrm{p}<0.01$. b) Comparison of upper airway collapsibility between controls and patients with oxyhaemoglobin desaturation index (ODI 4$)<10$ and ODI $4 \geq 10$. Bars indicate SD. $\uparrow$ : different from controls and patients with ODI $4<10, \mathrm{p}<0.003$ and $\mathrm{p}<0.03$, respectively. For definitions see legend to figure 3 .

\section{Discussion}

The results of the present study suggest that not only the upper airway size but also the upper airway collapsibility whilst awake is changed in patients with upper airway obstruction during sleep. We demonstrated the use of a simple digital fluoroscopic technique to evaluate the upper airway size and dynamics over the respiratory cycle. Velopharyngeal collapsibility, in particular, seemed to be critical to determine the upper airway obstruction during sleep. This is in agreement with earlier findings that the velopharynx is the area where upper airway collapse most often begins $[2,12,15,16,35,36]$. Oropharyngeal obstruction may also occur, usually promoted by increased negative inspiratory pressure after primary velopharyngeal obstruction.

Increased BMI is a considerable risk factor for snoring, with and without OSA. In our study, BMI had a linear correlation with collapsibility at the velopharyngeal 
level, but not with the airway size, supporting the importance of the collapsibility in addition to the airway size itself. SCHWARTZ et al. [28] reported that weight loss is associated with decreases in upper airway collapsibility in OSA, partially supporting our results.

The static-charge-sensitive bed (SCSB) is a noninvasive method to distinguish episodes of apnoea, hypopnoea or IRR. The clinical importance of partial upper airway obstruction has recently been emphasized [37]. Partial upper airway obstruction, even in the absence of apnoea episodes, may cause sleep fragmentation and induce sleepiness or insomnia, symptoms that are reversible by active therapy. It has been proposed that partial upper airway obstruction may herald more severe obstruction and the obstructive sleep apnoea syndrome. Therefore, partial upper airway obstruction should be diagnosed, and its effective treatment could potentially reduce the risk for later development of the obstructive sleep apnoea syndrome.

The relative ADmin at the hypopharyngeal level was larger in patients with $\mathrm{CO}$ than patients with minor and major PO combined. PoLo and co-workers [33, 34] suggested that airway collapse during sleep is favoured by a relatively wide hypopharynx because the large hypopharyngeal airway would leave the soft palate exposed to direct inspiratory suction, promoting the total obstruction of the upper airway. Although some investigators have reported that the hypopharynx of OSA patients are narrower than normal subjects, our results using digital fluoroscopy were consistent with the suggestion of POLO and co-workers [33,34], although the number of our patients with severe OSA was limited.

Previous studies of upper airway size in snorers with and without OSA are conflicting. HAPONIK et al. [11] and BOHLMAN et al. [13] reported that the airway crosssectional area was smaller in patients with OSA than in control subjects in the nasopharynx, oropharynx and hypopharynx on conventional CT; however, STAUFFER et al. [14] failed to demonstrate such a difference. SURATT et al. [12] reported that the pharyngeal cross-sectional area was smaller in patients with OSA than in normal control subjects in the region posterior to the soft palate but not in other parts of the pharynx. Conventional CT has several limitations. The dynamic change of the upper airway during the long scanning time $(2-5 \mathrm{~s})$ may affect measurement of the airway size because the upper airway size varies during tidal ventilation. The slice positioning may not be accurate because only transverse images can be obtained and the slice thickness is usually $8-10 \mathrm{~mm}$, in spite of the complex anatomy of the upper airway. Finally, the partial volume effect may affect the measurement of airway size. Some investigators $[9,10$, 16] have employed ultrafast CT to evaluate dynamic change of the upper airway during breathing, and have concluded that patients with OSA had a smaller crosssectional area in the oropharynx and nasopharynx. However, inaccurate slice positioning remains a problem even using ultrafast CT. The insufficient time and spatial resolutions of CT may at least partially explain the discrepancies with respect to upper airway size. The new technique of digital fluoroscopy provides dynamic information with improved time and spatial resolutions. Therefore, it is well adapted for accurate determination of the most narrow parts of the upper airway.
Digital fluoroscopy is better than conventional fluoroscopy for evaluation of the pharyngeal airway. By digital subtraction technique, it is easy to confirm that the patient's head does not move during examination, and to determine the images with ADmin and ADmax. Edgeenhancement technique may also be useful for clearly outlining a pharyngeal airway. There is a cost benefit using digital fluoroscopy, the examination time is shorter than CT, and there is a lower irradiation dose.

In prior studies into upper airway collapsibility (or compliance) of snoring patients with and without OSA, either negative or positive pressures have been applied to the upper airway and the cross-sectional area has been measured using conventional CT or acoustic reflection technique $[19,21-28]$. These studies have demonstrated that the upper airways of habitual snorers without apnoea are more collapsible than those of nonsnorers, but less collapsible than those with OSA. Recently, ultrafast CT has been employed for evaluation of the upper airway without applied pressure interventions [9, 10]. Those studies have concluded that the upper airway of snorer/ mildly apnoeic and apnoeic subjects at the retropalatal and retroglossal levels are more distensible than those of normal controls. In digital fluoroscopy, the subjects are spontaneously nose-breathing without external pressure, which would affect the physiological state of the upper airway. There was a significant correlation between the respiratory abnormalities during the night and the collapsibility while awake, although the collapsibility during sleep might be more relevant to OSA. The collapsibility measured in our study is likely to reflect both the intrinsic tissue properties of the pharyngeal walls, and the effect of pharyngeal muscle tone.

This study included snoring patients for whom an operative therapy had been chosen. In our hospital, patients with severe obstructive sleep apnoea syndrome are primarily treated with nasal continuous positive airway pressure (nCPAP). Therefore, only six subjects with severe OSA were included. All of them had discontinued nCPAP after a trial period.

The cause of OSA is multifactorial and differs in different patients. The multifarious cause of OSA may partially explain why the airway dimension and collapsibility at the velopharyngeal level were not significantly different between complete obstructors and controls. Although nine snorers revealed a collapsibility of $0 \%$ at the velopharyngeal level, all the patients were classified in the minor PO group. This result is not surprising because the collapsibility of the upper airway in the relatively mild snorers may be similar to controls. The multifactorial cause of snoring may also partially explain this result.

The epiglottis may be responsible for OSA in some patients, but abnormalities of the epiglottis are difficult to evaluate using digital fluoroscopy. Digital fluoroscopy provides only a two-dimensional lateral view, so that only the anterior-posterior dimensions can be appreciated. In apnoeic patients, the airway had an anterior-posterior configuration unlike the normal airway, which had a horizontal configuration with the major axis in the lateral direction [9, 17]. This change of the upper airway shape cannot be shown from the lateral view of digital fluoroscopy. It is possible that the lateral dimension of the upper airway might be more important than the anteroposterior dimension in snorers. SCHWAB et al. [9] 
evaluated the collapsibility (distensibility) of the upper airway by ultrafast CT, and reported that the change of not only the lateral but also the anteroposterior airway dimension was observed during breathing. Although the evaluation of the anteroposterior airway dimension might not be enough, useful information was obtained in our study.

In six of the 33 patients, both ADmin and ADmax were 0 at the velopharyngeal level, in spite of nose-breathing. This does not mean that the airway was completely obstructed, since both ADmin and ADmax represent the narrowest anteroposterior dimensions on each image. We suppose that the narrowest part of the velopharynx is usually at the midline of the airway. The cross-sectional airway is not necessarily elliptical, and the lateral parts of the velopharynx may be open.

The control group was not weight-matched. The patients had significantly higher BMI than the controls. This is not a surprising finding because most patients with obstructive apnoea are obese. Results of two studies comparing upper airway size in patients with sleep apnoea and weight-matched controls [4, 27] are in agreement with those in our study. In addition, simply weight-matching subjects may not be an appropriate control because fat distribution may differ between the subject groups. Furthermore, the control group was not age-matched; the patients were significantly older than the controls. The results of three studies comparing upper airway collapsibility (or compliance) in patients with sleep apnoea and age-matched controls [19, 24, 26] are in agreement with those of the present study. In addition, there were no significant differences in age between three subject groups with snoring in the present study. No significant correlation was observed between the airway size, or collapsibility, and age. These findings support the concept that the disease state is a more important determinant of airway size and collapsibility than either age or obesity.

In conclusion, the upper airway size is decreased and collapsibility increased at the velopharyngeal level in snorers while awake compared with controls. The upper airways were more collapsible in obese than in nonobese patients, whereas the airway size did not correlate with body mass index. Digital fluoroscopy proved to be a useful tool for the evaluation of the upper airway dynamics.

\section{References}

1. Hudgel DW. Mechanisms of obstructive sleep apnea. Chest 1992; 101: 541-549.

2. Shepard JW, Gefter WB, Guilleminault C, et al. Evaluation of the upper airway in patients with obstructive sleep apnea. Sleep 1991; 14(4): 361-371.

3. Riley R, Guilleminault C, Herran J, Powell N. Cephalometric analysis and flow-volume loops in obstructive sleep apnea. Sleep 1983; 6: 303-311.

4. Rivlin J, Hoffstein V, Kalbfleisch J, McNicholas W, Zamel N, Bryan AC. Upper airway morphology in patients with idiopathic obstructive sleep apnea. Am Rev Respir Dis 1984; 129: 355-360.

5. Jamieson A, Guilleminault C, Partinen M, Quera-Salva MA. Obstructive sleep apneic patients have craniomandibular abnormalities. Sleep 1986; 9: 467-477.
6. Djupesland G, Lyberg T, Krogstad O. Cephalometric analysis and surgical treatment of patients with obstructive sleep apnea syndrome. Acta Otolaryngol 1987; 103: 551-557.

7. Partinen M, Guilleminault C, Quera-Salva MA, Jamieson A. Obstructive sleep apnea and cephalometric roentogenograms: the role of anatomic upper airway abnormalities in the definition of abnormal breathing during sleep. Chest 1988; 93: 1199-1205.

8. Strelzow VV, Blanks RI, Basile A, Strelzow AE. Cephalometric airway analysis in obstructive sleep apnea syndrome. Laryngoscope 1988; 98: 1149-1158.

9. Schwab RJ, Gefter WB, Hoffman EA, Gupta KB, Pack AI. Dynamic upper airway imaging during awake respiration in normal subjects and patients with sleep-disordered breathing. Am Rev Respir Dis 1993; 148: 1385-1400.

10. Galvin JR, Rooholamini SA, Stanford W. Obstructive sleep apnea: diagnosis with ultrafast CT. Radiology 1989; 171: 775-778.

11. Haponik EF, Smith PL, Bohlman ME, Allen RP, Goldman SM, Bleecker ER. Computerized tomography in obstructive sleep apnea. Am Rev Respir Dis 1983; 127: 221-226.

12. Suratt PM, Dee P, Atkinson L, Armstrong P, Wilhoit SC. Fluoroscopic and computed tomographic features of the pharyngeal airway in obstructive sleep apnea. Am Rev Respir Dis 1983; 127: 487-492.

13. Bohlman ME, Haponik EF, Smith PL, Allen RP, Bleecker ER, Goldman SM. CT demonstration of pharyngeal narrowing in adult obstructive sleep apnea. AJR 1983; 140: 543-548.

14. Stauffer JL, Zwillich CW, Cadieux RJ, et al. Pharyngeal size and resistance in obstructive sleep apnea. Am Rev Respir Dis 1987; 136: 623-627.

15. Crumley-RL, Stein-M, Gamsu-G, Golden-J. Determination of obstructive site in obstructive sleep apnea. Laryngoscope 1987; 97: 301-308.

16. Stein MG, Gamsu G, deGeer G, Golden JA, Crumley RL, Webb WR. Cine-CT in obstructive sleep apnea. AJR 1987; 148: 1069-1084.

17. Rodenstein DO, Dooms G, Thomas Y, et al. Pharyngeal shape and dimensions in healthy subjects, snorers, and patients with obstructive sleep apnoea. Thorax 1990; 45: 722-727.

18. Shellock FG, Schatz CJ, Julien P, et al. Occlusion and narrowing of the pharyngeal airway in obstructive sleep apnea: evaluation by ultrafast spoiled GRASS MR imaging. AJR 1992; 158: 1019-1024.

19. Brown IG, Bradley TD, Phillipson EA, Zamel N, Hoffstein V. Pharyngeal compliance in snoring subjects with and without obstructive sleep apnea. Am Rev Respir Dis 1985; 132: 211-215.

20. Douglas NJ, Polo O. Pathogenesis of obstructive sleep apnoea/hypopnoea syndrome. Lancet 1994; 344: 653-655.

21. Issa FG, Sullivan CE. Upper airway closing pressures in snorers. J Appl Physiol: Respirat Environ Exercise Physiol 1984; 57: 528-535.

22. Hoffstein V, Zamel N, Phillipson EA. Lung volume dependence of pharyngeal cross-sectional area in patients with obstructive sleep apnea. Am Rev Respir Dis 1984; 130: 175-178.

23. Bradley TD, Brown IG, Grossman RF, et al. Pharyngeal size in snorers, nonsnorers, and patients with obstructive sleep apnea. N Engl J Med 1986; 315: 1327-1331.

24. Suratt PM, Wilhoit SC, Cooper K. Induction of airway collapse with subatmospheric pressure in awake patients with sleep apnea. J Appl Physiol: Respirat Environ Exercise Physiol 1984; 57: 140-146. 
25. Suratt PM, Mctier RF, Wilhoit SC. Collapsibility of the nasopharyngeal airway in obstructive sleep apnea. Am Rev Respir Dis 1985; 132: 967-971.

26. Gleadhill IC, Schwartz AR, Schubert N, Wise RA, Permutt S, Smith PL. Upper airway collapsibility in snorers and in patients with obstructive hypopnea and apnea. Am Rev Respir Dis 1991; 143: 1300-1303.

27. Kuna ST, Bedi DG, Ryckman C. Effect of nasal airway positive pressure on upper airway size and configuration. Am Rev Respir Dis 1988; 138: 969-975.

28. Schwartz AR, Gold AR, Schubert N, et al. Effect of weight loss on upper airway collapsibility in obstructive sleep apnea. Am Rev Respir Dis 1991; 144: 494-498.

29. Salmi T, Telakivi T, Partinen M. Evaluation of automatic analysis of SCSB, airflow and oxygen saturation signals in patients with sleep related apneas. Chest 1989; 96: 255-261.

30. Svanborg E, Larsson H, Carlsson-Nordlander B, Pirskanen R. A limited diagnostic investigation for obstructive sleep apnea syndrome: oximetry and static-charge-sensitive bed. Chest 1990; 98: 1341-1345.
31. Polo O, Brissaud L, Sales B, Besset A, Billiard M. The validity of the static change sensitive bed in detecting obstructive sleep apnoeas. Eur Respir J 1988; 1: 330-336.

32. Polo O, Brissaud L, Fraga J, Dejean Y, Billiard M. Partial upper airway obstruction in sleep after uvulopalatopharyngoplasty. Arch Otolaryngol Head Neck Surg 1989; 115: 1350-1354.

33. Polo O, Tafti M, Fraga J, Porkka KVK, Dejean Y, Billiard M. Why don't all heavy snorers have obstructive sleep apnea? Am Rev Respir Dis 1991; 143: 1288-1293.

34. Polo O, Tafti M, Fraga J, Billiard M. Pharyngeal CT studies in patients with mild or severe upper airway obstruction during sleep. Sleep 1993; 16: S152-S155.

35. Hudgel DW, Hendricks C. Palate and hypopharynx: sites of inspiratory narrowing of the upper airway during sleep. Am Rev Respir Dis 1988; 138: 1542-1547.

36. Katsantonis GP, Walsh JK. Somnofluoroscopy: its role in the selection of candidates for uvulopalatopharyngoplasty. Otolaryngol Head Neck Surg 1986; 94: 56-60.

37. Guilleminault C, Stoohs R, Duncan S. Snoring. I. Daytime sleepiness in regular snorers. Chest 1991; 99: 40-48. 